\title{
"Lean bundles within Jordanian manufacturing SMEs and their effect on business performance"
}

\begin{tabular}{|c|c|}
\hline AUTHORS & $\begin{array}{l}\text { Khalil Al-Hyari iD http://orcid.org/0000-0002-9261-3538 } \\
\text { R https://publons.com/researcher/G-9986-2017 }\end{array}$ \\
\hline ARTICLE INFO & $\begin{array}{l}\text { Khalil Al-Hyari (2020). Lean bundles within Jordanian manufacturing SMEs and } \\
\text { their effect on business performance. Problems and Perspectives in } \\
\text { Management, 18(2), 302-315. doi:10.21511/ppm.18(2).2020.25 }\end{array}$ \\
\hline DOI & http://dx.doi.org/10.21511/ppm.18(2).2020.25 \\
\hline RELEASED ON & Thursday, 25 June 2020 \\
\hline RECEIVED ON & Wednesday, 18 March 2020 \\
\hline ACCEPTED ON & Tuesday, 16 June 2020 \\
\hline LICENSE & $\begin{array}{l}(\mathrm{cc}) \overline{\mathrm{EY}} \\
\text { This work is licensed under a Creative Commons Attribution } 4.0 \text { International } \\
\text { License }\end{array}$ \\
\hline JOURNAL & "Problems and Perspectives in Management" \\
\hline ISSN PRINT & $1727-7051$ \\
\hline ISSN ONLINE & $1810-5467$ \\
\hline PUBLISHER & LLC “Consulting Publishing Company "Business Perspectives" \\
\hline FOUNDER & LLC "Consulting Publishing Company "Business Perspectives" \\
\hline
\end{tabular}

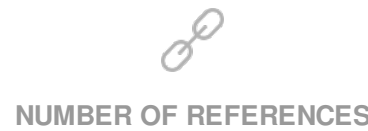

46
NUMBER OF FIGURES

2
NUMBER OF TABLES

4

(C) The author(s) 2021. This publication is an open access article. 


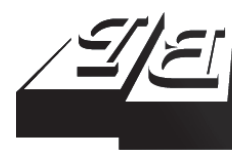

\section{BUSINESS PERSPECTIVES}

LLC "CPC "Business Perspectives" Hryhorii Skovoroda lane, 10, Sumy, 40022, Ukraine www.businessperspectives.org
Received on: $18^{\text {th }}$ of March, 2020 Accepted on: $16^{\text {th }}$ of June, 2020 Published on: $25^{\text {th }}$ of June, 2020

(c) Khalil Al-Hyari, 2020

Khalil Al-Hyari, Ph.D., Associate Professor, Faculty of Business, Project Management Department, Al-Balqa Applied University, Jordan.
This is an Open Access article distributed under the terms of the Creative Commons Attribution 4.0 International license, which permits unrestricted re-use, distribution, and reproduction in any medium, provided the original work is properly cited.

Conflict of interest statement: Author(s) reported no conflict of interest
Khalil Al-Hyari (Jordan)

\section{LEAN BUNDLES WITHIN JORDANIAN MANUFACTURING SMES AND THEIR EFFECT ON BUSINESS PERFORMANCE}

\begin{abstract}
Maximizing customer value and minimizing waste have become the heart of the formulation of SMEs in the manufacturing sector of Jordan to survive in the new global marketplace. Therefore, lean manufacturing philosophy is used in SMEs to improve performance regarding quality, delivery, and costs to become efficiently competitive, thus accomplishing sustainable economic growth. The current study was designed to analyze the extent to which lean management bundles are adopted by SMEs manufacturing organizations in Jordan and the effect on their performance. Data were collected from 278 manufacturing SMEs in Jordan based on a structured questionnaire. The theoretical relationships were examined using structural equation modeling. The results show that Total Quality Management (TQM) and Human Resources Management (HRM) lean bundles are positively associated with manufacturing SMEs' performance. The outcomes of this study may be considered as incentives for other practitioners and entrepreneurs of SMEs when implementing lean bundles by acknowledging the positive effect on their performance. Moreover, the findings of this study could be used in an internal checklist before and during the implementation of Lean Manufacturing (LM).
\end{abstract}

Keywords

small and medium enterprises (SMEs), manufacturing performance, developing countries, lean manufacturing, technological change

JEL Classification O14, L60

\section{INTRODUCTION}

As a response to the rapid technological development in the world, and to the market demands, firms of different sizes and from various sectors need to improve their product quality, provide faster delivery, and lower the costs to improve the efficiency of performance (Mohammad \& Oduoza, 2019; Shokri, Waring, \& Nabhani, 2016). Therefore, enterprises have to readjust their structure and competitive strategies (Alaskari, Ahmad, \& Pinedo-Cuenca, 2016; Alexander, Antony, \& Rodgers, 2019). Lean philosophy may just be the solution to this problem (Psomas, Antony, \& Bouranta, 2018).

Looking at it from a globalization standpoint, most studies have noted that SMEs are a source for improving competitiveness and contributors to increasing economic wealth (Prasanna \& Vinodh, 2013; $\mathrm{Hu}$, Mason, Williams, \& Found, 2015). SMEs are susceptible to the ever-changing world of business and it's increasingly demanding customers (Sajan, Shalij, Ramesh, \& Biju, 2017). Productivity, quality, customer satisfaction, and delivery are problems, which plague SMEs these days. To overcome these problems, SMEs have to tackle waste to meet quality requirements and delivery times, among other things, which can be achieved through the main characteristics of lean philosophy (Thanki \& Thakkar, 2019). 
Krafcik (1988) was the one who first suggested the concept "Lean" in 1988. The concept was based on the Japanese Toyota Production System (TPS). The target for the use of the lean concept was to minimize waste and time. This concept evolved into lean manufacturing in the USA and then diffused to other economies by various other main enterprises throughout the world to stay competitive in an increasingly globalized market (Shah \& Ward, 2007; Sahoo \& Yadav, 2018; Shrafat \& Ismail, 2019).

Lean philosophy is known throughout previous literature as a bundle of related practices installed as a system. The concurrent implementation of various lean bundles considerably enhances the operational performance depending on the synergistic relationships between them (Shah \& Ward, 2003; Furlan, Vinelli, \& Dal Pont, 2011; Al-Hyari, Abu Hammour, Abu Zaid, \& Haffar, 2016).

The fierce competition of today's marketplace is motivating SMEs in the manufacturing sector to redesign their strategies when it comes to cutting costs by reducing waste and eliminating non-value-added activities from a company's performance (Psomas et al., 2018; Gandhi, Sachdeva, \& Gupta, 2019). This goal has maximized the need for widespread enhancements in manufacturing leadership, customer relationships, strategic thinking, and employee satisfaction (Mohammad \& Oduoza, 2019). In this context, the adoption of a new philosophy such as lean that focuses on quality and flow appears as an alternative (Moya, Galvez, Muller, \& Camargo, 2019).

After evaluating the literature about the recent status of lean practices, principles, and bundles, it is quite clear that extensive research has been carried out regarding LM and its implementation in larger firms with little focus on SMEs (Hu et al., 2015; Psomas et al., 2018; Yadav et al., 2019a). Although lean thinking philosophy was one of the contemporary main investigation areas in operations management, as well as a gold standard of modern production management, there is a scarcity of studies focusing on lean in SMEs. Additionally, a great deal of skepticism remains concerning its applicability in SMEs (Yadav, Jain, Mittal, Panwar, \& Lyons, 2019b; Hu et al., 2015).

The issues related to LM philosophy have been a common research theme in the literature review for well over two decades, where SMEs research has been mostly conducted in developed countries. The majority of research about the lean implication in the SMEs sector has been carried out in Western settings (Hu et al., 2015). This strategy has received less attention and still relatively unheard of in developing countries (Albliwi, Antony, Arshed, \& Ghadge, 2017; AL-Najem, Dhakal, Labib, \& Bennett, 2013; Shrafat \& Ismail, 2019). Besides, little research has been done showing the significance of lean bundles on the performance of SMEs from a developing country's perspective, particularly in the Middle East region. Furthermore, the researcher noticed a lack of empirical investigations on the use of lean bundles within Jordanian manufacturing SMEs, which is the main interest of this study.

Distinguishing that lean bundles' implementation in manufacturing SMEs contributes to the performance and existence of such a sector in Jordan is an important phase in managing and avoiding the failure of this vital sector in Jordan. This study could be used as a dependable reference guide to researchers about SMEs that focus on LM activities. Also, the importance of the present research is that it could be used as a model and guide to those aiming to study lean bundles in other developing market economies.

Given this, the key research question is proposed: Is there a significant influence of lean bundles on the performance of manufacturing SMEs in Jordan?

Thus, the sub-questions are formulated as follows:

1. Do JIT bundles have a significant and positive influence on the performance of Jordanian SMEs in the manufacturing sector? 
2. Do HRM bundles have a significant and positive influence on the performance of Jordanian SMEs in the manufacturing sector?

3. Do TQM bundles have a significant and positive influence on the performance of Jordanian SMEs in the manufacturing sector?

This study is divided into six sections. After the introduction, the next section describes the extant literature on LM application in general, and within SMEs in particular, the research then moves on to the literature that highlights the implementation of LM at manufacturing SMEs in Jordan. The conceptual framework and the development of the research hypotheses are discussed in section 2. The research methodology employed in this study is discussed in section 3. Next, the analysis and discussion of the main research findings, implications, and limitations of the study, as well as some suggestions for further research, are discussed in sections 4 and 5. The conclusions are discussed in final section.

\section{LITERATURE REVIEW}

\subsection{Lean application in SMEs}

SMEs have always been thought of as the mainstay of emerging markets throughout the world as they considerably add to their economic growth regarding employment creation, innovation, and volume of manufacturing production ( $\mathrm{Hu}$ et al., 2015; Sajan et al., 2017). SMEs in Turkey comprise 99\% of all business organizations and employ $53 \%$ of the labor force in the manufacturing sector (Demirbag, Tatoglu, Tekinkus, \& Zaim, 2006). Likewise, Mohammad and Oduoza (2019) pointed out that about $95 \%$ of the industrial population in Kurdistan Region of Iraq (KRI) belongs to SMEs and account for about $80 \%$ of the total employment of the industrial labor. Jordanian SMEs constituted more than $98 \%$ of the total number of registered companies, $60 \%$ of formal jobs, and $50 \%$ of the GDP (JYES, 2017).

SMEs are typically well-known for their basic organizational structure, flexible production process, low risk, and receptivity to change, which create a favorable environment for lean initiatives (Yadav, Jain, Mittal, Panwar, \& Sharma, 2019a). Thus, along with being motivated by the success of lean implementation in large organizations, SMEs also have commenced implementing lean into their business practices.

Psomas et al. (2018) posited that SMEs could implement lean philosophy more than larger enterprises because they are thought of as more flexible when it comes to changing their pro- cesses and quickly respond to the seemingly ever-changing requirements of consumers. Besides, when compared to LEs, SMEs can provide personalized products or services where LEs cannot as they are based on mass production, which is recognized as a source of competition and the foundation in the development of manufacturing industry for promoting sustainable development to economies (Shrafat \& Ismail, 2019). Recently, since large enterprises depend essentially on SMEs, researchers concentrate on examining the way of increasing the performance of the SMEs (Ramadas \& Satish, 2017).

Alaskari et al. (2016) stated that it remains challenging for firms to choose the best suitable lean tool to be implemented, particularly concerning the SMEs whose information of lean tools and related principles is insufficient (Yadav et al., 2019a). Furthermore, Hu et al. (2015) and Mohammad and Oduoza (2019) believe that most of these enterprises fear that adopting LM is both time and money consuming, causing financial difficulties in addition to their misgivings about the tangibility of its outcomes and the benefits they may reap from its implementation.

Compared to large firms, SMEs may find difficulties in LM use (Dresch, Veit, Lima, Lacerda, \& Collatto, 2019). SMEs firms are very slow in adopting lean practices because they suppose that the implementation of a lean system is overwhelming, and comes with expensive and ongoing operational costs, in addition to lack of sufficient finances, absence of leadership, lack of multi-skilled employees, inappropriate organizational culture, 
archaic manufacturing technologies, and general lack of knowledge about the techniques used in LM (Sahoo \& Yadav, 2017; Sahoo \& Yadav, 2018; Shrafat \& Ismail, 2019; Dresch et al., 2019; Mohammad \& Oduoza, 2019).

Today, SMEs recognize lean as a well-respected approach that can support organizations in their endeavors to compete more effectively and accomplish sustainable economic growth (Shah \& Ward, 2003; Shrafat \& Ismail, 2019). However, several already established competitive strategies like TQM and LM are highly appropriate in large enterprises (LEs). Therefore, it is crucial to improve competitive strategies relevant to SMEs (Ramadas \& Satish, 2017). From the previous points, applying lean in the context of SMEs would be a vital topic to be investigated.

\subsection{Lean application in manufacturing SMEs sector}

Global competition has intensified pressure on SMEs to implement lean. Nevertheless, lean implementation is not restricted to the automobile sector alone; rather, the benefits of lean have been garnered by other sectors as well, including manufacturing, service, construction, and health sector, which have witnessed the positive effects that lean has had on the operational, financial, and sustainable performance of the organization (Al-Hyari et al., 2016; Shah \& Ward, 2007; Yadav et al., 2019a). Lean management can be what manufacturing SMEs turn to for enhancing their performance regarding quality, delivery, and costs, which, in turn, will increase operational performance (Shah \& Ward, 2007; Knol, Slomp, Schouteten, \& Lauche, 2019).

Thanks to the continued advancements in manufacturing and the improvements in operational management practices, LM has become more and more significant in manufacturing development. For the last twenty years or so, manufacturing companies working in rapidly and greatly competitive markets have welcomed the principles of lean thinking with open arms (Sahoo \& Yadav, 2018). Thus, by attempting to enhance their ability to know and stimulate the culture of LM, several enterprises are measuring and assessing the present position of their processes in a way that allows them to implement LM philosophy by systemati- cally managing waste to develop processes and operations in an endless attempt to decrease losses, and reduce the effort and time required for production (Dresch et al., 2019; Shrafat \& Ismail, 2019).

Large firms rely on a perfect network of suppliers; most of them are SMEs (Knol et al., 2019). According to Sahoo and Yadav (2018), the Indian government realized the significance of manufacturing as a competitive weapon. Thus, they found that LM is considered competitive for SMEs since it contributes to decreasing manufacturing costs with better-quality process flows and reducing the time of engineering.

Manufacturers have implemented various LM practices, tools, and techniques to create the best promising values and decrease non-value added activities. However, for many organizations, this is a complex and difficult task to accomplish effectively. Nevertheless, manufacturing SMEs struggle to improve enhancement routines and implement lean bundles. In the context of SMEs, LM initiatives pose further challenges (Mohammad \& Oduoza, 2019). With some manufacturers, lean practices are not applied correctly due to internal issues such as their dearth of information and understanding of lean, local culture, and business skills (Sahoo \& Yadav, 2018). A majority of manufacturing companies that have applied LM have their own unique way of assessing lean practices. It is certainly true that SMEs have unique features and specific success standards when it comes to lean application, which can vary quite a bit from large ones' arrangements.

Most developing countries agree that there are simply not enough data on this subject and that the implementation of LM has been restricted. Regardless of the benefits that can be derived, SMEs in developing countries, such as Asia and the Middle East regions, still lack the will to implement lean bundles. There is still a shortage in the studies that tackle the degree of lean implementation, and how to promote for its use in manufacturing SMEs sector (Hu et al., 2015; Psomas et al., 2018). Added to that is the lack of awareness of the issues related to lean implementation in manufacturing SMEs in contrast to large enterprises. The current study would try to fill in this gap by overcoming these challenges. 
Because of the Jordanian government's manufacturing policies, manufacturing industries in the country are anticipating high levels of economic growth and competitiveness; moreover, Jordan is also emerging as one of the Middle East's most preferred manufacturing destinations (Thanki \& Thakkar, 2019). Based on the statistics department's report in Jordan, the industrial institutions in Jordan for the year 2017 is almost 17,000, and about $98 \%$ of them are small and medium enterprises. This sector's importance lies in the large number of employees who are continuously being hired in the manufacturing SMEs sector in Jordan (DOS, 2020).

Despite this opportunity for growth in Jordan's manufacturing sector, other problems such as innovation, sustainability, and cost reduction need urgent attention. In developing countries like Jordan, the manufacturing sectors face various obstacles and opportunities, some of which are ubiquitous to all countries, others only found in developing countries, and it is the challenges faced by the latter that need to be addressed by manufacturers. This research seeks to recognize the most effectively adopted lean bundles in developed countries and decide whether or not they can be validly and significantly used in the same way in developing countries.

One of the highest growth sectors in Jordan is manufacturing; thus, manufacturing SMEs have a golden opportunity to come out of the shadows and conquer the global market. However, to do so, Jordanian manufacturers need to implement quality programs that will allow them to be more competitive in the international marketplace. Fierce challenges with competition have motivated several SMEs to implement lean tools to improve their firms' efficacy and effectiveness (Thanki \& Thakkar, 2019; Sahoo \& Yadav, 2018). To gauge how Jordanian SMEs adapt to and practice lean bundles implementation, more thorough research must be conducted on the subject, as little has been written about it. Therefore, the novelty of this study is encouraged by the research gap. It lies in investigating how the lean bundles affect the performance and confirm the relationship among them in the Jordanian manufacturing SMEs.
2. CONCEPTUAL FRAMEWORK AND HYPOTHESES DEVELOPMENT

Lean has been globally used in different enterprises to develop both performance and competitive advantages (Ramadas \& Satish, 2017). However, when it comes to obtaining the performance benefits that manufacturers get when they implement the lean system, some manufacturers are still skeptical. Therefore, the conclusions were not consistent regarding lean's impact on performance.

Regarding any relationships between the degree of lean practices' use and operational consequences, Bonavia and Marin (2006) noticed few, if any. Valente, Sousa, and Moreira (2019) found that, in Portuguese SMEs, lean manufacturing's impact on overall performance was positive. Actually, in their survey of 425 Indian SMEs on the degree of lean practices implementation and the relationship between lean and operational performance, Yadav et al. (2019b) stated that Indian SMEs are applying a few of lean practices; however, this limited lean application is having a positive influence on their performance. According to Sahoo and Yadav (2018), little firms achieve important enhancements by implementing lean, while Bortolotti, Danese, and Romano (2013) found a negative correlation between lean practices, principles, and performance.

To enhance the performance of organizations, various methods and tools are located under the lean strategy's umbrella (Sahoo \& Yadav, 2018). After reviewing a plethora of literature, Shrafat and Ismail (2019) stated that there is no complete agreement in the classification of the most common lean practices that aim to improve organizational performance since researchers differ in their categorizing, reflecting variances in the context of the researchers. Created at an operational level, lean is made up of several tools and practices that were designed to help support the implementation of lean thinking in the manufacturing firms (Valente et al., 2019).

D. Wickramasinghe and V. Wickramasinghe (2011) recognize the lean concept as an array of 
related practices connected as a system. The performance of organizations improves since the application of the total set of lean practices/bundles leads organizations to enhance their performance, caused by the relationships between practices, as lean practices/bundles operate effectively, and unify the greatest practices and concepts (Dal Pont, Furlan, \& Vinelli, 2008). The practices and principles of lean are connected in a strong manner, whose main goal is to reduce waste through eliminating or minimizing provider, customer, and internal variability (Psomas et al., 2018).

Lean practice was grouped into three advanced level bundles, i.e., just in time (JIT), while waste minimization and flow management were measured according to Rahman et al.'s (2010) study, which inspects the amount to which LM practices are implemented by Thai manufacturing companies and their influence on a firm's performance. After reviewing the literature about LM, Sahoo and Yadav (2018) provided us with a list of lean practices implemented in SMEs used to recognize and decrease waste while maximizing flexibility, including VSM, 5S workplace organization, total productive maintenance, process standardization, Kanban and pull production methods, and visual signals.

Shrafat and Ismail (2019) also selected seven practices that had already been adopted by the manufacturing industry: H5S, PP/Kanban, supplier JIT, SPC, TPM, SME, and CF. In their study, Knol et al. (2019) measured only practices that had previously been applied by Shah and Ward (2007), which included ten lean practices "PM, CP, pull, flow, low setup, supplier feedback, JIT delivery, developing suppliers, involved customers and involved employees", all of which have become standards for measuring this kind of construct.

The previous literature review determines the use of a limited number of lean bundles in SMEs. According to Yadav et al. (2019b), SMEs cannot implement full lean philosophy because of the restraints of capitals, information, and manpower. Furthermore, in Brazilian SMEs, Filho, Ganga, and Gunasekaran (2016) identified that just three out of ten lean practices are considered a core of lean implementations, leading them to conclude that SMEs piecemeal the application of lean practices in that country. Other researchers combined lean tools and practices into four bundles: JIT, TPM, TQM, and HRM (Shah \& Ward, 2003). Some researchers study only three of these bundles. After reviewing the related literature about the bundles that influence lean application, AlHyari et al. (2016) selected three bundles - JIT, TQM, and HRM - to test the complimentary influences of these bundles on the performance. Also, they found that because of the synergistic influences between practices, the general performance is more than the performance contributions of each of its parts.

There is no literature mentioning the influences of lean bundles on operations of Jordanian manufacturing SMEs. The main purpose of this research is to fill this gap by investigating the influence of lean bundles in the operations of Jordanian manufacturing SMEs. Also, this research planned to clarify and outspread the literature on this theme. The research study agrees with the enormous majority of the literature, which proposed that the influence of various lean practices/bundles over performance measures is positive (Sajan et al., 2017; Shrafat \& Ismail, 2019; Valente et al., 2019; Thanki \& Thakkar, 2019; Yadav et al., 2019b).

More precisely, the evaluation of the implementation of lean bundles was based on a tool created by Shah and Ward (2003) and Al-Hyari et al. (2016), which consists of five items for JIT, five items for TQM, five items for HRM. The subjective performance has been used where respondents assessed organizational performance based on market share, overall sales, profitability, and satisfaction since the objective financial performance are not available easily at SMEs sector because they are privately held, therefore, unimportant to provide detailed financial information (Rua, França, \& Ortiz, 2018; Imran, Abdul Hamid, \& Azizb, 2018). When it comes to profitability, competitiveness development, customer, and employee satisfaction, measuring business performance is presented in favor of assessing lean outcomes suitably in SMEs (Mohammad \& Oduoza, 2019).

Regarding the JIT technique, firms have to postpone unnecessary resources until they 


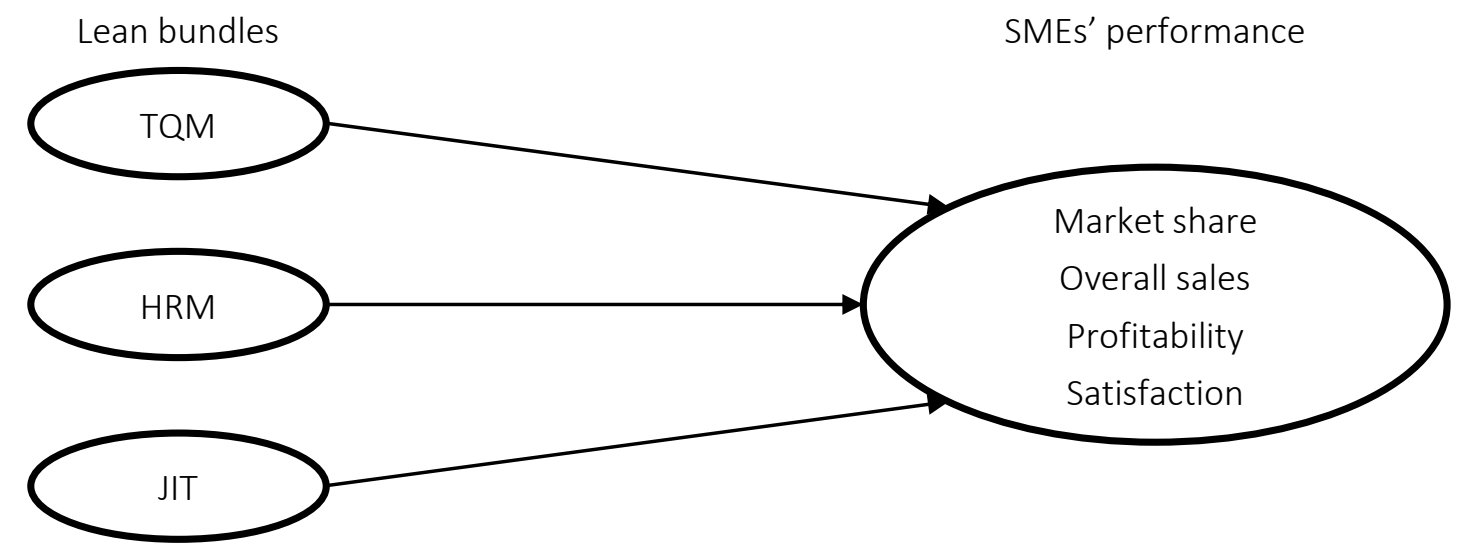

Figure 1. Research framework

are required to "produce the right quantity of the right item at the right time" (Rahman, Laosirihongthong, \& Sohal, 2010; Valente et al., 2019). According to Shah and Ward (2003) and Belekoukias, Garza-Reyes, and Kumar (2014), the JIT bundle contains practices that eventually decrease waste, such as waste of inventory and waste of time waiting. Both service and manufacturing companies employ practices to produce an end product or service, which is the main competitive benefits of JIT management (Al-Hyari et al., 2016).

TQM is a management viewpoint to achieve high-quality customer satisfaction and firm performance by taking advantage of management, employees, suppliers, and customers and contains practices, for example, CI/kaizen (Shah \& Ward, 2003; Al-Hyari et al., 2016). To achieve customer satisfaction at a minimum cost, developing countries have embraced TQM concepts to enhance their firms' products, procedures, and services, leading to improved performance (Imran et al., 2018). Lean practices/bundles geared at eliminating manufacturing procedure variance has improved TQM and, in turn, led to CI (Shah \& Ward, 2007). Applying the kaizen methodology is an efficient and a dependable way to overcome all types of shortfalls, leading to enhanced quality and productivity most cost-effectively in the caravan repairing project in Jordan (Al-Hyari et al., 2019).

Finally, as a lean principle, HRM aims to eliminate quality defects using the tools made up of devices designed to avoid mistakes, full working systems, and visual control systems (Belekoukias et al., 2014). HRM is built on employee participation and commitment. It contains practices as multi-functional employees/cross-training, streamlined organizational structure with decentralized authority, continuous training, job security, multi-skilling and quality circles (Shah \& Ward, 2007; Alsmadi, Almani, \& Jerisat, 2012; Martínez-Jurado, Moyano-Fuentes, \& Gómez, 2013; Valente et al., 2019). Effective leadership is required to be successful in implementing lean bundles with an organizational strategy in a coherent manner (Hu et al., 2015).

Based on the literature review, this research implements a conceptual framework and a set of hypotheses. Figure 1 illustrates the study framework used to clarify the influence of the lean bundles on SMEs' performance. Therefore, the author hypothesizes that synchronized implementation of multiple aspects of lean bundles is positively associated with SMEs' performance in the manufacturing sector. Thus, the main hypotheses are formulated as follows:

H1: JIT bundles have a positive and significant influence on the performance of manufacturing SMEs in Jordan.

H2: TQM bundles have a positive and significant influence on the performance of manufacturing SMEs in Jordan.

H3: HRM bundles have a positive and significant influence on the performance of manufacturing SMEs in Jordan. 


\section{RESEARCH METHODOLOGY}

The current study uses the quantitative scientific approach based primarily on a structured survey questionnaire since it is the best-favored method in the lean studies (Al-Hyari et al., 2016; Psomas et al., 2018), whereas an empirical investigation was carried out to determine the effects of lean bundles on the performance of Jordanian manufacturing SMEs. Data collection took place between June 2019 and November 2019. The sample frame was constructed by merging the databases of SMEs from the Jordanian Ministry of Industry and Trade, the Chamber of Commerce, and the General Statistics Department. SMEs were defined as companies that employ between 1 and 249 employees.

Frameworks for categorizing lean bundles and performance were developed after reviewing the prior studies on lean manufacturing to test the hypotheses and affirm the validity and reliability of the instrument (Sajan et al., 2017; Sahoo \& Yadav, 2018). Content validity of the draft questionnaire was guaranteed by pretesting it with an expert group of professionals from manufacturing firms and academics having substantial knowledge in lean practices. The questionnaire was modified according to the recommendations of the professional team.

To precisely evaluate the extent of lean implementation in manufacturing SMEs, five items for JIT, five items for TQM, five items for HRM, and four items for SMEs performance were included in the survey. All of the lean bundles were rated on a five-point Likert scale, which ranged from "strongly disagree" (1) to "strongly agree" (5). Four items regarding performance are measured on a five-point Likert scale ranging from "much worse" to "much better". Questionnaires rated with fivepoint Likert scale are easy to answer and clear (Sajan et al., 2017). Furthermore, the SEM analysis was achieved using AMOS software.

The questionnaire consisted of three parts. The first part included the organization's profile and personal information of the respondents. The second looks at the implementation of lean bundles. Finally, the third was devoted to the operations of the SMEs. In total, 400 questionnaires were dis- tributed to SMEs owners/managers. After an initial review of 278 returned and completed questionnaires, it was deemed that questionnaires are suitable for statistical processing, a response rate of 69.5 percent, which was considered satisfactory for subsequent analysis.

\section{DATA ANALYSIS AND THE RESULTS}

\subsection{Sample characteristics}

Table 1 shows that, concerning the demographic profile of the respondents and the descriptive data of their organizations, a majority of respondents (75.6\%) were between 20 and 55 years. As they are more interested in growth, younger owners/managers are more inclined to participate in business development activities by looking for different ways to both raise the value and quality of their products and satisfy the needs of their customers at the same time. Around $71.95 \%$ of the total number of managers as respondents has more than ten years of working experience in manufacturing SMEs. Therefore, the accuracy and originality of the information have been achieved. All the manufacturing SMEs as respondents employ less than 250 employees. It is believed that, by achieving this response rate, the SMEs were well represented.

The participants are all highly educated and experienced. Better educated managers seem to be more proactive and concerned with the LM program in their organizations; therefore, they are willing to objectively assess the advantages of the lean concept to improve the performance of their organizations. Manufacturing companies from health and personal care, food, chemicals, pharmaceuticals, textiles and garments, and furniture sectors are involved in this research. Because the responses from different sectors of SMEs were used, the results can be generalized to a large degree through diverse SMEs of various products. It was critical to choose respondents with the necessary knowledge and experience and who were directly involved through LM implementation within their organizations. Hence, around (39.57\%) of the respondents were from quality departments, (35.97\%) from the senior executive managers, 
while $(24.46 \%)$ were from the departmental managers and others.

Table 1. Sample characteristics

\begin{tabular}{|c|c|c|}
\hline Measure & Value & $\%$ \\
\hline \multirow{2}{*}{ Gender } & Male & 68.7 \\
\hline & Female & 31.3 \\
\hline \multirow{4}{*}{ Age } & 20 less than 24 & 18 \\
\hline & 24 less than 34 & 32.4 \\
\hline & 34 less than 55 & 25.2 \\
\hline & More than 55 years & 24.4 \\
\hline \multirow{4}{*}{ Academic qualification } & High school or less & 3.59 \\
\hline & Bachelor & 50.36 \\
\hline & Master & 35.98 \\
\hline & $\mathrm{PhD}$ & 10.07 \\
\hline \multirow{4}{*}{ Size of the company } & $1-9$ & 7.19 \\
\hline & $10-49$ & 46.77 \\
\hline & $50-249$ & 46.04 \\
\hline & 250 and above & - \\
\hline \multirow{4}{*}{ Experience } & Less than 4 years & 10.07 \\
\hline & $4-10$ years & 17.99 \\
\hline & $11-20$ years & 53.96 \\
\hline & More than 20 years & 17.99 \\
\hline \multirow{6}{*}{ Firm sector } & Pharmaceutical & 2.16 \\
\hline & Food & 15.11 \\
\hline & Health and personal care & 10.79 \\
\hline & Chemical & 39.57 \\
\hline & Textile and garment & 17.99 \\
\hline & Furniture & 14.38 \\
\hline \multirow{4}{*}{ Management level } & Quality manager & 39.57 \\
\hline & Departmental manager & 14.39 \\
\hline & Production manager & 35.97 \\
\hline & Others & 10.07 \\
\hline
\end{tabular}

\subsection{Validity and reliability}

The results of both reliability and validity analysis of construct tools are presented in Table 2. Using Cronbach's $\alpha$, the internal consistency reliability of all constructs can be measured. According to the results, Cronbach's alpha value for four constructs is above the threshold value of 0.6 , which shows satisfactory internal consistency reliability of all proportions (Sekaran \& Bougie, 2016).

Through confirmatory factor analysis and correlation analysis, Table 2 shows that all the results are appreciably well above the recommended value since all items are loaded on their principal construct. With the lowest value being 0.791 , it is the condition for convergent validity. Statistically significant loading of all items, which is higher than the recommended value of 0.7 , is also the condition for composite reliabilities (CR) (Gefen et al., 2000). As the average variance extracted (AVE) is more than 0.50 , and the square root of AVE is larger than each correlation coefficient, discriminant validity can be approved since it is consistent with the threshold values suggested by Fornell and Larcker (1981).

To examine the unidimensionality of the lean practices that underwent the principal component analysis with varimax rotation, Table 2 shows the results. Three higher-level constructs have been produced by using the principal component analysis. These are TQM (five scales), HRM (five scales), and JIT (five scales). Four dimensions of manufacturing SMEs performance also underwent the principal component analysis. A single higher-level construct of performance has also been produced according to the principal component analysis, which is valid and reliable.

Table 2. Measurement items, validity and reliability analysis

\begin{tabular}{|c|c|c|c|c|}
\hline Measures & $\begin{array}{l}\text { Factor } \\
\text { loading }\end{array}$ & AVE & CR & $\begin{array}{c}\text { Cronbach's } \\
\text { alpha }(\alpha)\end{array}$ \\
\hline \multicolumn{5}{|c|}{ Total Quality Management (TQM) bundle } \\
\hline 1 & .846 & \multirow{5}{*}{.696} & \multirow{5}{*}{.919} & \multirow{5}{*}{.890} \\
\hline 2 & .876 & & & \\
\hline 3 & .827 & & & \\
\hline 4 & .816 & & & \\
\hline 5 & .803 & & & \\
\hline \multicolumn{5}{|c|}{ Human Resource Management (HRM) bundle } \\
\hline 1 & .815 & \multirow{5}{*}{.714} & \multirow{5}{*}{.926} & \multirow{5}{*}{.899} \\
\hline 2 & .851 & & & \\
\hline 3 & .855 & & & \\
\hline 4 & .847 & & & \\
\hline 5 & .858 & & & \\
\hline \multicolumn{5}{|c|}{ Just in Time (JIT) bundle } \\
\hline 1 & .862 & \multirow{5}{*}{0.699} & \multirow{5}{*}{0.921} & \multirow{5}{*}{.892} \\
\hline 2 & .838 & & & \\
\hline 3 & .844 & & & \\
\hline 4 & .843 & & & \\
\hline 5 & .791 & & & \\
\hline \multicolumn{5}{|c|}{ Manufacturing SMEs Performance } \\
\hline 1 & .855 & \multirow{4}{*}{0.704} & \multirow{4}{*}{0.905} & \multirow{4}{*}{.859} \\
\hline 2 & .853 & & & \\
\hline 3 & .854 & & & \\
\hline 4 & .793 & & & \\
\hline
\end{tabular}


Table 3. Descriptive statistics and correlations

\begin{tabular}{|c|c|c|c|c|}
\hline Variables & 1 & 2 & 3 & 4 \\
\hline Just in Time (JIT) & 0.834 & - & - & - \\
\hline Human Resource Management (HRM) & $.680^{* *}$ & 0.845 & - & - \\
\hline Total Quality Management (TQM) & $.626^{* *}$ & $.576^{* *}$ & 0.836 & - \\
\hline Manufacturing SMEs performance & $.584^{* *}$ & $.560^{* *}$ & $.718^{* *}$ & 0.839 \\
\hline
\end{tabular}

Note: The bold numbers on the diagonal are the square root of the AVEs. ${ }^{*} p<0.05{ }^{* *} p<0.01$.

The correlation between three lean bundles and manufacturing SMEs performance were examined using Pearson's correlation analysis. According to the results in Table 3, the correlation coefficients for the variables under investigation were reasonably high between (.718) and (.560).

\subsection{Hypotheses testing results}

The structural model established by path diagram is presented in Figure 2. The fit indices are $\chi 2 / d f=(2.481), \quad$ RMSEA $=(.073), \quad$ TLI $=(.931)$, $\mathrm{CFI}=(.942)$, and SRMR $=(.045)$. Consistent with the threshold values recommended by $\mathrm{Hu}$ and Bentler (1999), the model can be accepted.

The outcomes of the SEM with the standardized coefficients and $t$-values are shown in Figure 2 and Table 4.

H1: HRM bundle has a positive and significant influence on the performance of manufacturing SMEs in Jordanian. The coefficient for this path is significant $(\beta=.273, p<0.05)$. This supports Hypothesis H1.

H2: TQM bundle has a positive and significant influence on the performance of manufac- turing SMEs in Jordanian. The coefficient for this path is significant $(\beta=.718, p<0.05)$. This supports Hypothesis H2.

H3: JIT bundle has a positive and significant influence on the performance of manufacturing SMEs in Jordanian. The coefficient for this path is significant $(\beta=.195, p<0.05)$. This does not support Hypothesis H3.

This study fundamentally emphasizes the effect of lean bundles on the performance of the Jordanian manufacturing SMEs, which plays a significant role in Jordanian economic development. The current study has found a positive relationship between TQM and HRM bundles and SMEs performance.

\section{DISCUSSION}

The outcomes of this study show that the most significant lean bundles were found to be TQM. The findings of this study suggest that the majority of manufacturing SMEs must have TQM capabilities, as it can afford to enhance their business reputation when it comes to product and service quality that meet the customer's needs and allow them to effectively and efficiently compete with their rivals,

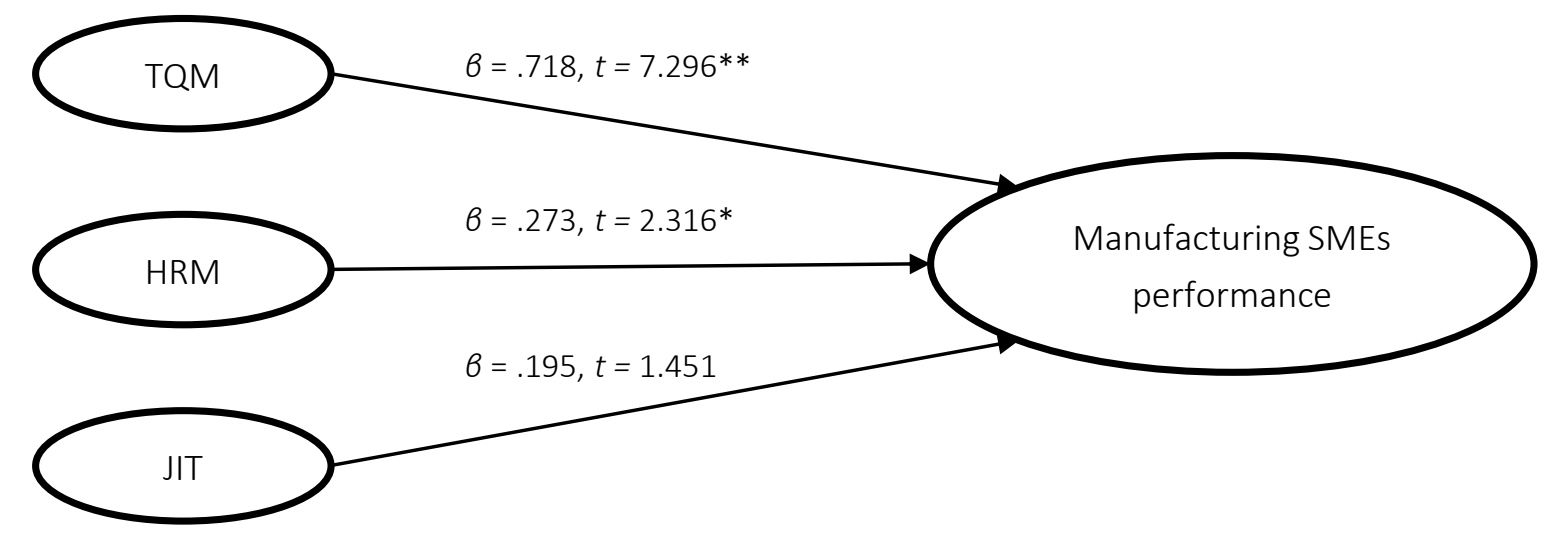

Figure 2. Hypotheses testing results 
Table 4. Path analysis for the constructs of the study

\begin{tabular}{|c|c|c|c|}
\hline Path & Estimate & C.R. & $\mathbf{p}$ \\
\hline SMEs performance $\leftarrow$ Top Quality Management (TQM) & .718 & 7.296 & .000 \\
\hline SMEs performance $<$ Human Resource Management (HRM) & .273 & 2.316 & .021 \\
\hline SMEs performance $\leftarrow$ Just in Time (JIT) & .195 & 1.451 & .147 \\
\hline
\end{tabular}

thereby leading them to maximum success in both the local and international markets. Furthermore, SMEs managers/owners should be aware of the fact that TQM is one of the approaches that would enhance their business's competiveness by helping them avoid any errors or mistakes they may face. These results are in agreement with the previous literature (Basu \& Bhola, 2016).

The outcomes of this study also highlight the fact that to improve the performance of organizations, SMEs managers must concentrate on applying effective and flexible strategic human resource management as proper training. Education is also important to ensure that lean's implementation is successful. These results agree with the previous literature, which indicates that education and training have a positive effect on performance (AlHyari et al., 2016).

Despite the importance of JIT, the skepticism regarding the benefits of performance, which are obtainable from implementing JIT bundles, can be attributed to the fact that the majority of manufacturing SMEs in Jordan do not implement the modern techniques, which has been used in inventory control according to the high cost of implementing and maintaining these systems despite its advantages for SMEs. One explanation for these findings is that businesses with larger firm size and unit revenues are most apt to be more experienced in modern technology and innovations for using lean practices that may enhance their performance (Al-Hyari et al., 2016). This result is consistent with Muchaendepi et al. (2019) that SMEs adopting inventory analysis techniques lag behind larger organizations since the cost of applying and keeping the system is comparatively high. Jordan is a small country with limited natural resources; Jordanian SMEs import a large amount of their material from the international market. This implies a higher risk of costly production delays because of late arrival due to the increasing cost of transportation, which is a benefit for local providers. Also, the Jordanian market is not widely spread within its region since it is relatively considered small.

Given that SMEs are considerably globally contributing to the manufacturing economy, it can be supposed that SMEs' quick implementation of lean bundles has become a significant factor in its success. In the current turbulent business environment, manufacturing SMEs need never-ending enhancement and more effectual techniques to meet the customer's needs from products or services. Cost minimization without affecting the quality has to be the target for all manufacturing SMEs to continue in this competitive international economy and improve their competitive advantage over their competitors by using the LM philosophy as a road map (Sahoo \& Yadav, 2018).

This study makes a few contributions to the current body of knowledge since the results are useful for other researchers, scholars, and practitioners. The study on lean bundles has received limited care, particularly for developing countries like Jordan. Therefore, the results of this study have reinforced the state-of-the-art in this area. Also, this work is expected to help researchers, academics, practitioners, and experts in lean manufacturing at the Jordanian SMEs sector in planning for a successful lean transformation. The results confirm the findings of previous research that the LM program is appropriate both in developed and developing economies. These results comply with several studies that showed the same results, e.g., Shrafat and Ismail (2019) and Al-Hyari et al. (2016).

The present study results are limited to Jordanian manufacturing SMEs, which could not be generalized for other countries or other sectors. Therefore, they could be recommended for further research to be performed in other countries and other sectors. The study's sample size was relatively small (28) to examine the influencing relationships of the se- 
lected constructs. So, it is suggested to statistically validate the influencing relations with large sample size. Moreover, the study was cross-sectional; hence, a longitudinal study must be performed to reinforce the findings. There might be other lean practices and bundles, which can affect the operations of manufacturing SMEs. Thus, this study might be extended to verify other lean bundles and practices that might influence SMEs performance; also, the performance measure is subjective, which is based on the perception of the respondents. Future research should consider other dimensions of performance, such as objective and sustainable performance.

\section{CONCLUSION}

As SMEs are the cornerstone of the Jordanian economy, the capability of SMEs to be active in both local and global markets greatly influences the long-term competitiveness of Jordan. Subsequently, Jordanian government should support this important sector to keep and improve its role in developing the Jordanian economy by investing a large amount of money in promotion, embark on a LM program to enhance organizational performance, which, as a result, will improve Jordan's economic performance. More focus is needed by the top management of Jordanian manufacturing SMEs to consult the same field's specialists and follow the successful benchmarks of LM that had been used in other firms to improve its implementation level and sustainability.

Also, it is recommended that the current production and operation approaches be changed using contemporary techniques to decrease costs. Lean bundles can lead to the reduction of manufacturing costs, and subsequently, develop the production quality and improvement of new products at its best price. SMEs are required to develop themselves by showing effective and more dedicated leadership and management commitment, enhancing their staff's skills and expertise, and exhibiting a conducive organizational culture to guarantee the successful implementation of lean philosophy in their organizations.

\section{AUTHOR CONTRIBUTIONS}

Conceptualization: Khalil Al-Hyari.

Formal analysis: Khalil Al-Hyari.

Investigation: Khalil Al-Hyari.

Methodology: Khalil Al-Hyari.

Project administration: Khalil Al-Hyari.

Resources: Khalil Al-Hyari.

Software: Khalil Al-Hyari.

Validation: Khalil Al-Hyari.

Writing - original draft: Khalil Al-Hyari.

Writing - review \& editing: Khalil Al-Hyari.

\section{REFERENCES}

1. Alaskari, O., Ahmad, M., \&

Pinedo-Cuenca, R. (2016).

Development of a Methodology to Assist Manufacturing SMEs in the Selection of Appropriate Lean Tools. International Journal of Lean Six Sigma, 7(1), 62-84. https://doi. org/10.1108/IJLSS-02-2015-0005

2. Albliwi, S., Antony, J., Arshed, N., \& Ghadge, A. (2017). Implementation of Lean Six Sigma in Saudi Arabian organisations: Findings from a survey. International Journal of Quality \& Reliability Management, 34(4), 508-529. https://doi.org/10.1108/ IJQRM-09-2015-0138

3. Alexander, P., Antony, J., \& Rodgers, B. (2019). Lean Six Sigma for Small- and Medium-Sized Manufacturing Enterprises: A Systematic Review. International
Journal of Quality \& Reliability Management, 36(3), 378397. https://doi.org/10.1108/ IJQRM-03-2018-0074

4. Al-Hyari, K., Abu Hammour, S., Abu Zaid, M., \& Haffar, M. (2016). The Impact of Lean Bundles on Hospital Performance: Does Size Matter. International Journal of Health Care Quality Assurance, 29(8), 877-894. 
https://doi.org/10.1108/IJHCQA-07-2015-0083

5. Al-Hyari, K., Abu Zaid, M., Arabeyyat, O., Al-Qwasmeh, L., \& Haffar, M. (2019). The Applications of Kaizen Methods in Project Settings: Applied Study in Jordan. The TQM Journal, 31(5), 831-849. https://doi.org/10.1108/TQM-032019-0078

6. AL-Najem, M., Dhakal, H., Labib, A., \& Bennett, N. (2013). Lean Readiness Level within Kuwaiti Manufacturing Industries. International Journal of Lean Six Sigma, 4(3), 280-320. https://doi. org/10.1108/IJLSS-05-2013-0027

7. Alsmadi, M., Almani, A., \& Jerisat, R. (2012). A Comparative Analysis of Lean Practices and Performance in the UK Manufacturing and Service Sector Firms. Total Quality Management \& Business Excellence, 23(3-4), 381-396. https://doi.org/1 $0.1080 / 14783363.2012 .669993$

8. Basu, R., \& Bhola, P. (2016). Impact of Quality Management Practices on Performance Stimulating Growth: Empirical Evidence from Indian IT Enabled Service SMEs. International Journal of Quality \& Reliability Management, 33(8), 11791201. https://doi.org/10.1108/ IJQRM-10-2015-0153

9. Belekoukias, I., Garza-Reyes, J. A., \& Kumar, V. (2014). The Impact of Lean Methods and Tools on the Operational Performance of Manufacturing Organizations. International Journal of Production Research, 52(18), 5346-5366. https://doi.org/ 10.1080/00207543.2014.903348

10. Bortolotti, T., Danese, P., \& Romano, P. (2013). Assessing the Impact of Just-in-Time on Operational Performance at Varying Degrees of Repetitiveness. International Journal of Production Research, 51(4), 1117-1130. https://doi.org/10.1080/00207543. 2012.678403

11. Dal Pont, G., Furlan, A., \& Vinelli, A. (2008). Interrelationships among Lean bundles and their effects on Operational Performance. Operations Management Research, 1(2),
150-158. https://doi.org/10.1007/ s12063-008-0010-2

12. Demirbag, M., Tatoglu, E., Tekinkus, M., \& Zaim, S. (2006). An analysis of the relationship between TQM implementation and organizational performance: Evidence from Turkish SMEs. Journal of Manufacturing Technology Management, 17(6), 829-847. https://doi. org/10.1108/17410380610678828

13. Department of Statistics. (2020). Jordan in Figures 2017. Retrieved from http://dosweb.dos.gov.jo/ar/ industry/

14. Dresch, A., Veit, D., Lima, P., Lacerda, D., \& Collatto, D. (2019). Inducing Brazilian Manufacturing SMEs Productivity with Lean Tools. International Journal of Productivity and Performance Management, 68(1), 69-87. https://doi.org/10.1108/ IJPPM-10-2017-0248

15. Filho, M. G., Ganga, G. M. D., \& Gunasekaran, A. (2016). Lean Manufacturing in Brazilian Small and Medium Enterprises: Implementation and effect on Performance. International Journal of Production Research, 54(24), 7523-7545. https://doi.org/10.1080 /00207543.2016.1201606

16. Fornell, C., \& Larcker, D. F. (1981) Evaluating Structural Equation Models with Unobservable Variables and Measurement Error. Journal of Marketing Research, 18(1), 39-50. Retrieved from https://www.jstor.org/ stable/3151312

17. Furlan, A., Vinelli, A., \& Dal Pont, G. (2011). Complementarity and Lean Manufacturing Bundles: An Empirical Analysis. International Journal of Operations \& Production Management, 31(8), 835-850. https://doi. org/10.1108/01443571111153067

18. Gandhi, S., Sachdeva, A., \& Gupta, A. (2019). Impact of Service Quality on Satisfaction and Loyalty at ManufacturerDistributor Dyad: Insights from Indian SMEs. Journal of Advances in Management Research, 16(1), 91-122. https://doi.org/10.1108/ JAMR-12-2017-0120
19. Gefen, D., Straub, D., \& Boudreau, M. C. (2000). Structural Equation Modeling and Regression: Guidelines for Research Practice. Communications of the Association for Information Systems, 4(7), 1-77. https://doi. org/10.17705/1CAIS.00407

20. Hu, L., \& Bentler, M. (1999). Cutoff Criteria for fit Indexes in Covariance Structure Analysis: Conventional Criteria Versus New Alternatives. Structural Equation Modelling, 6(1), 1-55. https://doi. org/10.1080/10705519909540118

21. Hu, Q., Mason, R., Williams, S., \& Found, P. (2015). Lean Implementation within SMEs: A Literature Review. Journal of Manufacturing Technology Management, 26(7), 980-1012. https://doi.org/10.1108/JMTM-022014-0013

22. Imran, M., Abdul Hamid, S., \& Azizb, A. (2018). The Influence of TQM on Export Performance of SMEs: Empirical evidence from Manufacturing Sector in Pakistan using PLS-SEM. Management Science Letters, 8, 483-496. https:// doi.org/10.5267/j.msl.2018.3.003

23. Jordanian Young Economists Society. (2017). Challenges facing SMEs and what is needed to empower SMEs sector in Jordan (online). Retrieved from https://www.kas.de/documents/252038/253252/7_dokument_dok_pdf_41279_2. pdf/571a302c-7e84-7fdd-fa5b$72 \mathrm{~d} 2 \mathrm{ecc} 44 \mathrm{e} 85$ ? version $=1.0$ $\& \mathrm{t}=1539652585795$

24. Knol, W., Slomp, J., Schouteten, R., \& Lauche, K. (2019). The Relative Importance of Improvement Routines for Implementing Lean Practices. International Journal of Operations \& Production Management, 39(2), 214-237. https://doi.org/10.1108/ IJOPM-01-2018-0010

25. Krafcik, J. (1988). The triumph of lean production. Sloan Management Review, 30(1), 41-52. Retrieved from https://www.lean. org/downloads/MITSloan.pdf

26. Martínez-Jurado, P., MoyanoFuentes, J., \& Gómez, P. (2013). 
HR Management During Lean Production Adoption. Management Decision, 51(4), 742-760. https://doi. org/10.1108/00251741311326545

27. Mohammad, I., \& Oduoza, C. (2019). Lean-Excellence Business Management for Manufacturing SMEs Focusing on KRI. International Journal of Productivity and Performance Management, 69(3), 519539. https://doi.org/10.1108/ IJPPM-11-2018-0389

28. Moya, C., Galvez, D., Muller, L., \& Camargo, M. (2019). A new Framework to Support Lean Six Sigma Deployment in SMEs. International Journal of Lean Six Sigma, 10(1), 58-80. https://doi. org/10.1108/IJLSS-01-2018-0001

29. Muchaendepi, W., Mbohwa, C., Hamandishe, T., \& Kanyepe, J. (2019). Inventory Management and Performance of SMEs in the Manufacturing Sector of Harare. Procedia Manufacturing, 33, 454461. https://doi.org/10.1016/j. promfg.2019.04.056

30. Prasanna, M., \& Vinodh, S (2013). Lean Six Sigma in SMEs: An Exploration through Literature Review. Journal of Engineering, Design and Technology, 11(3), 224-250. https://doi.org/10.1108/ JEDT-01-2011-0001

31. Psomas, E., Antony, J., \& Bouranta, N. (2018). Assessing Lean Adoption in Food SMEs: Evidence from Greece. International Journal of Quality $\&$ Reliability Management, 35(1), 64-81. https://doi.org/10.1108/ IJQRM-05-2016-0061

32. Rahman, S., Laosirihongthong, T., \& Sohal, A. (2010). Impact of Lean Strategy on Operational Performance: A Study of Thai Manufacturing Companies. Journal of Manufacturing Technology Management, 21(7), 839-852. https://doi. org/10.1108/17410381011077946

33. Ramadas, T., \& Satish, K. P. (2018). Identification and Modeling of Process Barriers: Implementing Lean Manufacturing in Small-and Medium-Size Enterprises. International
Journal of Lean Six Sigma, Vol. ahead-of-print No. ahead-ofprint. https://doi.org/10.1108/ IJLSS-09-2016-0044

34. Rua, O., França, A., \& Ortiz, R. (2018). Key Drivers of SMEs Export Performance: The Mediating effect of Competitive Advantage. Journal of Knowledge Management, 22(2), 257-279. https://doi.org/10.1108/JKM-072017-0267

35. Sahoo, S., \& Yadav, S. (2018). Lean Implementation in Small- and Medium-Sized Enterprises: An Empirical Study of Indian Manufacturing Firms. Benchmarking: An International Journal, 25(4), 1121-1147. https:// doi.org/10.1108/BIJ-02-2017-0033

36. Sajan, M. P., Shalij, P. R., Ramesh, A., \& Biju, B. (2017). Lean Manufacturing Bractice in Indian Manufacturing SMEs and their effect on Sustainability Performance. Journal of Manufacturing Technology Management, 28(6), 772-793. https://doi.org/10.1108/JMTM-122016-0188

37. Sekaran, U., \& Bougie, R. J. (2016). Research Methods for Business: A Skill Building Approach (Vol. 7). John Wiley and Sons.

38. Shah, R., \& Ward, P. T. (2003). Lean Manufacturing: Context, Bractice Bundles, and Performance. Journal of Operations Management, 21(2), 129-149. https://doi.org/10.1016/ S0272-6963(02)00108-0

39. Shah, R., \& Ward, T. (2007). Defining and Developing Measures of Lean Production. Journal of Operations Management, 25(4), 785-805. https://doi.org/10.1016/j. jom.2007.01.019

40. Shokri, A., Waring, T., \& Nabhani, F. (2016). Investigating the Readiness of People in Manufacturing SMEs to Embark on Lean Six Sigma Projects: An Empirical Study in the German Manufacturing Sector International Journal of Operations \& Production Management, 36(8), 850-878. https://doi.org/10.1108/ IJOPM-11-2014-0530
41. Shrafat, F., \& Ismail, M. (2019). Structural Equation Modeling of Lean Manufacturing Practices in a Developing Country Context. Journal of Manufacturing Technology Management, 30(1), 122-145. https://doi.org/10.1108/ JMTM-08-2017-0159

42. Thanki, S., \& Thakkar, J. (2019). An Investigation on Lean-Green Performance of Indian Manufacturing SMEs. International Journal of Productivity and Performance Management, 69(3), 489517. https://doi.org/10.1108/ IJPPM-11-2018-0424

43. Valente, C., Sousa, P., \& Moreira, M. (2019). Assessment of the Lean effect on Business Performance: The Case of Manufacturing SMEs. Journal of Manufacturing Technology Management, 31(3), 501-523. https://doi.org/10.1108/ JMTM-04-2019-0137

44. Wickramasinghe, D., \& Wickramasinghe, V. (2011). Perceived Organisational Support, Job Involvement and Turnover Intention in Lean Production in Srilanka. International Journal of Advanced Manufacturing Technology, 55(5-8), 817-830. https://doi.org/10.1007/s00170010-3099-Z

45. Yadav, V., Jain, R., Mittal, M., Panwar, A., \& Sharma, M. (2019a). An Appraisal on Barriers to Implement Lean in SMEs. Journal of Manufacturing Technology Management, 30(1), 195-212. https://doi.org/10.1108/ JMTM-12-2017-0262

46. Yadav, V., Jain, R., Mittal, M., Panwar, A., \& Lyons, A. (2019b). The impact of lean Practices on the Operational Performance of SMEs in India. Industrial Management \& Data Systems, 119(2), 317-330. https://doi. org/10.1108/IMDS-02-2018-0088 